DOI: 10.12957/demetra.2018.35259

\title{
Imagens e discursos sobre corpos, famílias e subjetividades: manifestações estigmatizantes, idealizações e desigualdades na arena de debate
}

\section{Images and discourse on bodies, families and subjectivities: stigmatizing manifestations, idealizations and inequalities in the debate arena}

Este número traz uma Seção Temática com artigos que buscam problematizar os discursos e as imagens construídas do corpo e as subjetividades em contextos de múltiplas relações, dentre as quais aqueles onde a família se insere; discursos e imagens circulantes na vida cotidiana, mas também no mundo acadêmico, que informam a construção de determinados modelos, conceitos e práticas voltados à saúde e à alimentação. Esta iniciativa pretendeu estimular, incentivar e acolher análises estruturadas a partir de diferentes referenciais teóricos e metodológicos sobre o tema, construídos à luz de perspectivas mais abrangentes, reunindo estudos que ressaltam como manifestações estigmatizantes e modos de perceber a imagem de si e do outro impactam a subjetividade. Tais expressões - assentadas em imagens socialmente construídas do corpo, situadas em contextos como o das práticas profissionais em diferentes campos permeados de tensões e envolvendo relações familiares - exprimem, em grande medida, padrões de alimentação saudável e de beleza que merecem a dedicação de um ponto de vista da pesquisa, visto que se apresentam aos nossos olhos de modo naturalizado e, aparentemente, cristalino. A partir deste cenário de temas presentes na vida e no cotidiano, insuflado pelas mais variadas representações e coerções contemporâneas, encontramo-nos ante um espaço de reflexão sobre as moralidades acerca da alimentação, da saúde, do corpo perfeito, da obesidade, das desigualdades, do consumo de estilos de vida e de subjetividades.

Este investimento resulta aqui, como já indicamos em números temáticos anteriores, em uma colaboração acadêmica entre os Programas de Pós-graduação em Alimentação, Nutrição e Saúde (UERJ), em Nutrição (UFRJ) e em Ensino em Biociência e Saúde (Instituto Oswaldo Cruz-Fiocruz), por meio de intercâmbio de seus docentes e da oferta de disciplinas em comum. São movimentos dedicados a fazer dialogar diferentes análises e compreensões dos aspectos humanos e sociais sobre o tema, mas também propiciar e colaborar na ampliação de respostas aos problemas por nós enfrentados na sociedade contemporânea.

O principal desejo dos organizadores foi reunir esforços para estimular o alargamento das fronteiras disciplinares persistentes no meio acadêmico - apesar dos estímulos aos estudos interdisciplinares em curso em vários âmbitos da construção do conhecimento - que levam a uma fragmentação do mesmo e 
ao empobrecimento das análises dos fenômenos estudados. Em diferentes âmbitos do campo da Saúde, por exemplo, incluindo parcela significativa do campo da Alimentação e Nutrição, os temas em tela são abordados predominantemente do ponto de vista biologicista e mecanicista, apontando sua centralidade nos projetos de pesquisa no âmbito da Pós-graduação. Sabendo-se que estes conhecimentos gestados no interior da ciência informam as experiências subjetivas dos indivíduos, esta perspectiva tende a ofuscar e, muitas vezes, aprisionar as múltiplas e potenciais abordagens sobre o tema do corpo e da alimentação, dificultando o desdobramento de novos entendimentos acerca das imagens e dos discursos sobre o tema.

Desse modo, os textos aqui apresentados, frutos de diferentes trajetórias, singulares e coletivas, tratam de questões aparentemente diversas, mas que se entrelaçam trazendo conexões se vistos por perspectiva mais abrangente. $\mathrm{O}$ enfoque nos arranjos familiares em sua relação com aspectos clínicos se enlaça aqui nos artigos que abordam a alimentação saudável, seja pela ótica da subjetividade individual e familiar, seja pela via das novas propostas de Educação Alimentar e Nutricional que possibilitam uma ressignificação das práticas alimentares em termos da construção identitária entre mulheres e na modelação da infância. Do mesmo modo, nos artigos dedicados a pensar aspectos da imagem corporal e dos sentidos e significados do corpo, seja em um grupo social vinculado a instituições disciplinares, com o caso das mulheres encarceradas, ou instituições formadoras, como se apresenta na formação do nutricionista, evidenciam-se achados inusitados, bem como a busca pelo afastamento da abordagem recorrente de aplicação de testes e identificação quanto a satisfação ou insatisfação com a imagem corporal em determinados grupos populacionais. Ao investirem em uma análise que segue no sentido de propor novas formas de entendimento desses conceitos, esses trabalhos colocam questões relevantes, tanto para a formação, quanto à prática dos profissionais de saúde.

Esta iniciativa encontrou acolhimento na revista DEMETRA: Alimentação, Nutrição e Saúde, tendo em vista seu caráter interdisciplinar, que propicia e instiga reflexões ampliadas para o campo da Alimentação e Nutrição. A oportunidade de publicar tais abordagens neste veículo revela um relevante amadurecimento do periódico, por onde circulam pesquisas no campo da Alimentação e Cultura. Por fim, o objetivo desta Seção Temática foi reunir trabalhos que trouxessem um conjunto relevante de discursos sobre o tema, o que nos aponta também a necessidade de avançar ainda mais no acolhimento de diferentes perspectivas analíticas (sociológicas, antropológicas, históricas, psicológicas, etc.) que favoreçam um olhar mais diversificado e menos fragmentado da natureza humana, revelando a complexidade dos contextos de nossos estudos e a impossibilidade de abordá-los apenas na perspectiva das ciências biomédicas.

Editores convidados

Cristiane Marques Seixas - UERJ

Daniela Menezes Neiva Barcellos - UFRJ

Eliane Portes Vargas - FIOCRUZ

Flávia Milagres Campos - UNIRIO

Francisco Romão Ferreira - UERJ 